\title{
Ongoing large mumps outbreak in the Federation of Bosnia and Herzegovina, Bosnia and Herzegovina, December 2010 to July 2011
}

M Hukic (mirsadahukic@yahoo.com) ${ }^{1}$, J Ravlija², A Dedeic Ljubovic ${ }^{1}$, A Moro ${ }^{1}$, S Arapcic ${ }^{1}$, C P Muller ${ }^{3}$, J M Hübschen ${ }^{3}$

1. Institute of Clinical Microbiology, Clinical Centre University of Sarajevo, Sarajevo, Bosnia and Herzegovina

2. Institute of Public Health of Federation Bosnia and Herzegovina, Sarajevo, Bosnia and Herzegovina

3. Institute of Immunology, World Health Organization, European Regional Reference Laboratory for Measles and Rubella, Centre de Recherche Public-Santé/Laboratoire National de Santé, Luxembourg, Luxembourg

Citation style for this article:

Hukic M, Ravlija J, Dedeic Ljubovic A, Moro A, Arapcic S, Muller CP, Hübschen JM. Ongoing large mumps outbreak in the Federation of Bosnia and Herzegovina,

Bosnia and Herzegovina, December 2010 to July 2011.

Euro Surveill. 2011;16(35):pii=19959. Available online: http://www.eurosurveillance.org/ViewArticle.aspx?Articleld=19959

Article published on 1 September 2011

From December 2010 until the end of July 2011, 5,261 mumps cases were recorded in the Federation of Bosnia and Herzegovina, Bosnia and Herzegovina, leading to an incidence of $\mathbf{2 2 5 . 8}$ per $\mathbf{1 0 0 , 0 0 0}$. Fifteen to 19 year-olds ( $43 \%$ ) were most affected and $62 \%$ of cases were male. Mumps-specific IgM antibodies were found in about $70 \%$ of sera investigated, complications were reported in $41 \%$ of 81 hospitalised patients. The outbreak affected mainly those unvaccinated or unaware of their vaccination status and is probably due to vaccination failures during the war and postwar period (1992-1998).

In December 2010 the cantons of Zenica-Doboj $(n=40)$ and Central Bosnia $(n=34)$ reported an increased number of mumps cases to the Ministry of Health of Bosnia and Herzegovina. Subsequently, the number of mumps patients continued to rise and more cantons reported cases. By the end of July 2011, a total of 5,261 cases were reported to the Ministry of Health.

\section{Background}

Immunisation against mumps was introduced in Bosnia and Herzegovina in 1980 in form of a combined vaccine against measles, mumps and rubella (MMR) [1]. Until 1992, it was recommended to vaccinate children between one and 14 years of age without documented history of mumps, with one dose of MMR vaccine. Between 1992 and 1995, the war caused disruptions to the routine immunisation programme, in the country, and these disruptions continued also during the postwar period (1996-1998). In 2001, a two-dose schedule with MMR vaccine was implemented throughout the country, with the first dose given at the age of 12 months and the second dose at the age of seven years and no later than 14 years. The MMR vaccine produced by the Institute of Immunology Zagreb was used until 2009 and contained the L-Zagreb strain as component, and since 2010, the Glaxo SmithKline MMR vaccine containing the Jeryl Lynn strain is employed $[1,2]$. The average coverage with MMR vaccine for the Federation of Bosnia and Herzegovina between 1998 and 2009 ranged from $84 \%$ to $92 \%$ for the first dose, and from $53 \%$ to $92 \%$ for the second dose (Figure 1 ).

Mumps is a notifiable disease in Bosnia and Herzegovina and is reported on the basis of clinical symptoms and epidemiological data. Reporting of mumps is normally done by the doctors to the Institute for Public Health, which looks for epidemic evidence and provides information to the Ministry of Health.

The first reports on mumps in Bosnia and Herzegovina date back to 1956 [3]. In the period before 1980, when vaccination against mumps was introduced, morbidity was high with an incidence ranging from 189 to 253 cases per 100,000 inhabitants per year (Figure 2). After introduction of the vaccine, incidence decreased from 123 in 1981 to 3.5 in 1992. During the war from 1992 to 1995 , the reported incidence of mumps was between 7.8 and 5.1 , but reporting was irregular and underreporting is likely. Between 1999 and 2002, 25 smaller

\section{FIGURE 1}

Coverage of measles, mumps and rubella vaccine in the Federation of Bosnia and Herzegovina, Bosnia and Herzegovina, 1998-2009

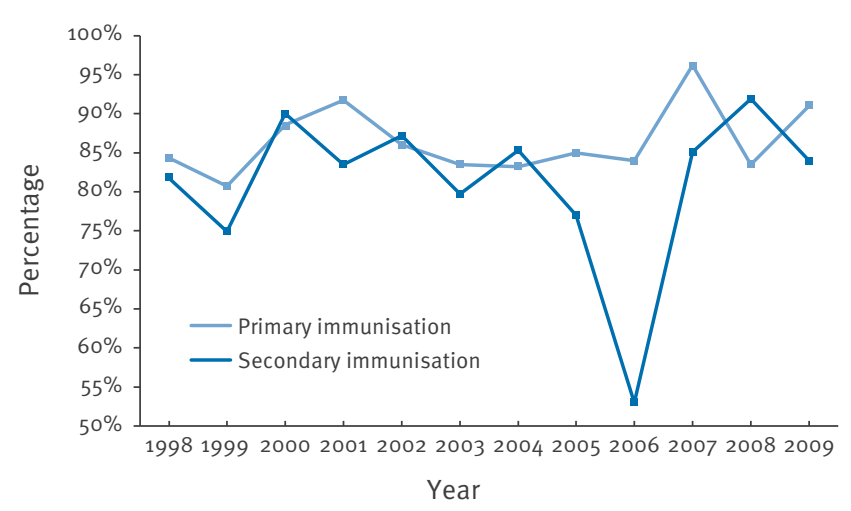


outbreaks were reported with a total of 2,743 cases. The last outbreak of mumps in Bosnia and Herzegovina occurred in 2002 with a total of 410 reported cases and until December 2010 only few cases were notified [4].

At the beginning of December 2010 a mumps outbreak started in the Federation of Bosnia and Herzegovina and is still currently ongoing. This report describes the mumps outbreak in the country and includes data from December 2010 until the end of July 2011.

\section{Description of the outbreak}

Since the start of the outbreak in December 2010, 5,261 cases have occurred in nine of the 10 cantons of the country, however, cantons are affected to a different extent. In December 2010, 85 cases were reported and the peak of the outbreak was in April 2011 with 1,240 cases reported (Figure 3 ).

The most severely affected cantons are Central Bosnia Canton ( $n=2,156$ cases), Zenica-Doboj Canton ( $n=1,695)$, Sarajevo Canton $(n=1,035)$ and Herzegovina-Neretva

\section{FIGURE 2}

Incidence of mumps cases, Bosnia and Herzegovina, January 1976-July 2011

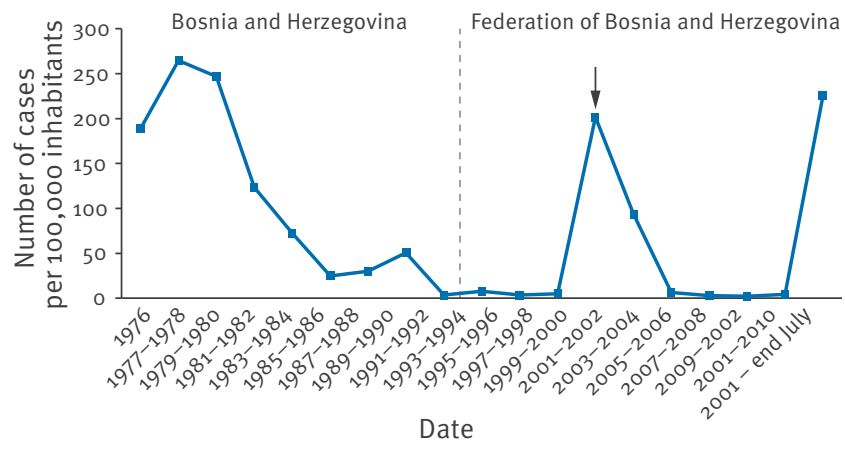

The dotted vertical line indicates a time point from which data is only shown for the Federation of Bosnia and Herzegovina.

The arrow indicates when a two-dose schedule of measles, mumps and rubella vaccine was implemented in Bosnia and Herzegovina.

\section{FIGURE 3}

Number of mumps cases per month, Federation of Bosnia and Herzegovina, Bosnia and Herzegovina, beginning December 2010-end July $2011(n=5,261)$

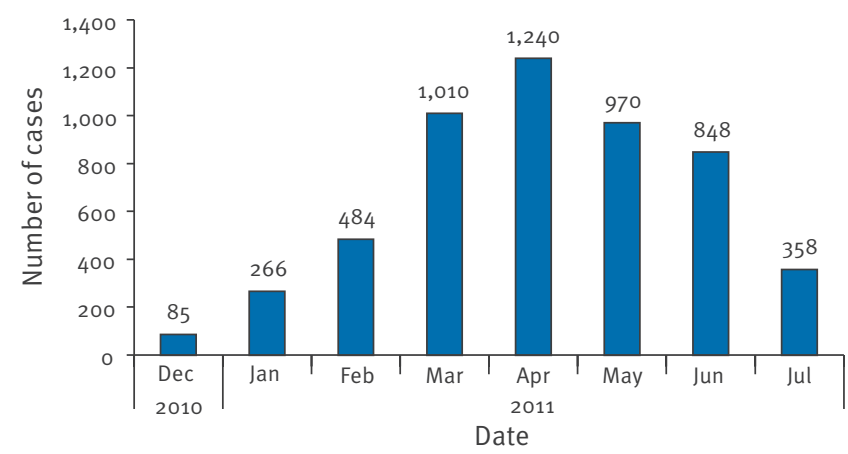

Canton $(n=326)$. Together they account for about $99 \%$ of all cases. Only few cases have been reported in Una-Sana, Tuzla, Bosnian Podrinje, West Herzegovina and West Bosnia cantons, and no cases from Posavina Canton (Figure 4).

For 5,219 patients, data on age and sex are available. The majority $(3,255 / 5,219 ; 62 \%)$ are male and the most affected age groups include the 15 to 19 year-olds $(2,232 / 5,219 ; 43 \%)$, followed by 20 to 29 year-olds $(1,254 / 5,219 ; 24 \%)$ (Figure 5).

Patients with serious clinical symptoms such as fever, temperature above 38.5 , swelling of the parotid and/ or salivary glands, and fatigue were hospitalised. A total of 81 patients were admitted to the Clinical Centre University of Sarajevo, but we have no data for other hospitals. The vast majority were male $(67 / 81,83 \%)$ and 30 of them had orchitis (30/67, 45\%). One female and two male patients had meningitis (3/81, $4 \%$ ).

\section{Vaccination status of cases}

For $34 \%$ of the cases $(1,774 / 5,219)$ vaccination status was unknown. About $33 \%$ of cases $(1,722 / 5,219)$ were unvaccinated, $18 \%(939 / 5,219)$ were vaccinated with one dose of a mumps-containing vaccine, and only $15 \%$ $(784 / 5,219)$ had received two doses (Figure 6).

\section{Laboratory findings}

Samples were collected for laboratory analysis from 104 cases: throat swabs from 32, throat swabs and serum from 48 and only serum from 24 of them. The cases' age ranged from seven to 48 years (median:

\section{FIGURE 4}

Cumulative number and geographical distribution of notified mumps cases, mumps outbreak, Federation of Bosnia and Herzegovina, Bosnia and Herzegovina, beginning December 2009-end July $2011(n=5,261)$

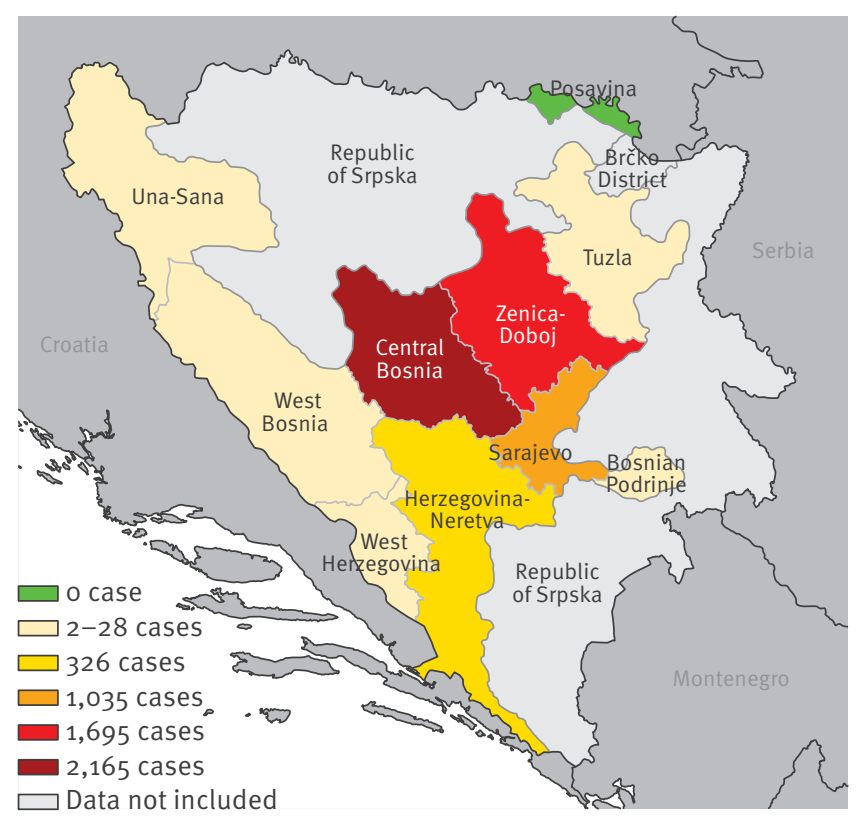


$22.15 \pm 7.47$ ) and $83 \%$ were male. All 72 serum samples were tested with the Siemens Enzygnost anti-parotitis virus kit for mumps-specific IgG and IgM antibodies. Sixty-eight samples were IgG positive (94\%), three were borderline and one was negative. A total of 50 samples were positive for IgM (69\%), eight were borderline and 14 were negative. The results of PCR and sequence analysis from throat swabs are pending.

\section{Control measures}

In March 2011, the Federal Minister of Health declared a mumps epidemic. It was recommended to increase the vaccination coverage with two doses of MMR vaccine in children between one and 14 years of age and some schools with increased case numbers were temporarily closed.

Other epidemic control measures by public health authorities, supported by doctors and/or teachers in the schools included: (i) health education, (ii) disseminating information about general and personal sanitary and hygienic measures to take, (iii) isolating infected persons and limiting contact with them, (iv) disinfection of articles of general use and (v) frequent

\section{FIGURE 5}

Number of cases in relation to age and sex, mumps outbreak, Federation of Bosnia and Herzegovina, Bosnia and Herzegovina, beginning December 2009-end July $2011(n=5,219)$

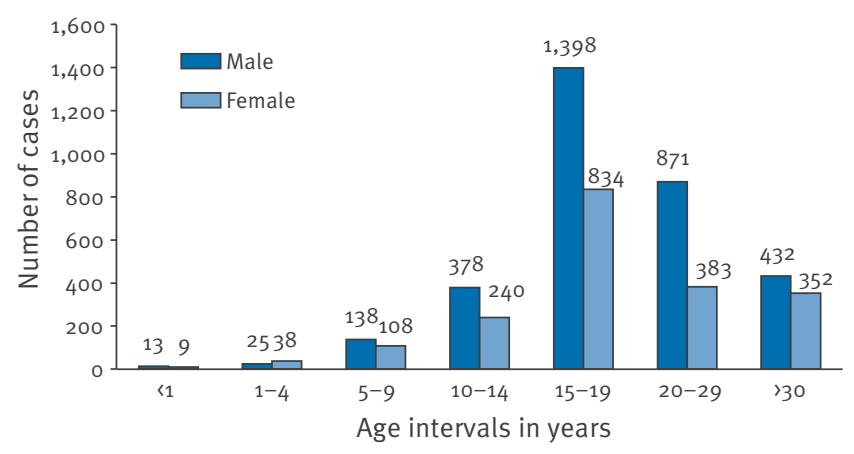

\section{FIGURE 6}

Vaccination status of patients, mumps outbreak, Federation of Bosnia and Herzegovina, Bosnia and Herzegovina, beginning December 2009-end July $2011(n=5,219)$

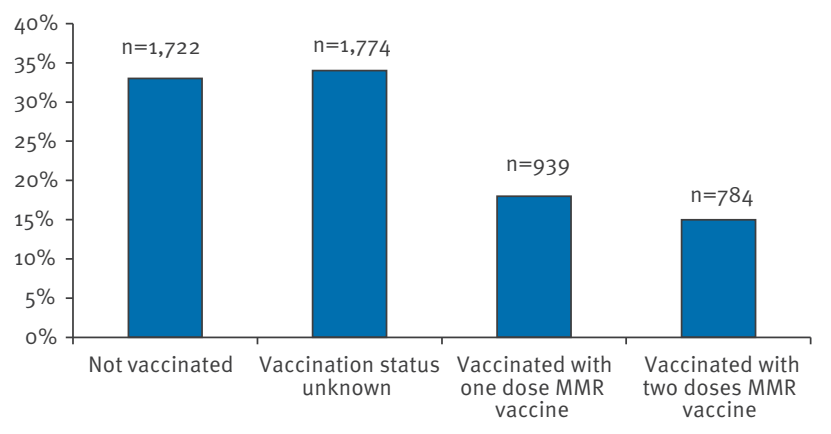

MMR: Measles, mumps, rubella hand washing in order to limit further spread of the disease. The control measures were in accordance with protocols for prevention and infection control.

\section{Discussion and conclusions}

In recent years, mumps outbreaks were reported from many countries all over the world [5-8]. In Bosnia and Herzegovina, disruption in the immunisation program during the war (1992-1995) and in the post-war period (1996-1998) left considerable numbers of children susceptible to measles, rubella and mumps [9]. The children, who were supposed to get their first vaccination between 1992 and 1998 are now between 14 and 20 years old and constitute a large proportion of the people affected by the current outbreak. Our data also show that most cases in the current outbreak (85\%) either did not know their vaccination status or reported being not or incompletely vaccinated.

The geographical regions with the highest case numbers in the current mumps outbreak largely concur with the areas that were most severely affected during previously reported rubella and measles epidemics $[10,11]$. Also, during the war from 1992 to 1995 , immunisation was not fully implemented across the entire territory of Bosnia and Herzegovina. The program of immunisation was not the same across the Cantons. Two doses of vaccine were used in the Posavina, HerzegovinaNeretva and West Herzegovina cantons while in other cantons only one dose was implemented. Some small outbreaks occurred in Una-Sana Canton and Tuzla Canton and they had additional vaccination with monovalent parotitis vaccine and that is the probably reason for the smaller number of cases in these cantons in the current outbreak.

Similarly to the rubella outbreak in 2010 [10], more males contracted the disease $(62 \%)$ and the most severely affected age group were young adolescents (15 to 19 years of age, $43 \%$ ). High numbers of mumps cases in male adolescents were reported recently from several countries, such as Israel, the United Kingdom, the Netherlands and the United States [5,12-14].

The majority of cases reported during the current outbreak were diagnosed based on clinical symptoms, sometimes supported by epidemiological data. Only a few samples were collected from non-hospitalised patients for laboratory confirmation, as the clinical picture was considered typical. In about $70 \%$ of the serum samples, mumps-specific IgM antibodies were detected, confirming the clinical diagnosis.

Information about complications and hospitalisations related to the outbreak is incomplete. The available data point to complications in about $7 \%$ of the female (meningitis) and $48 \%$ of the male (meningitis and orchitis) hospitalised patients, however, total numbers of cases are low. Symptomatic meningitis has been reported to occur in up to $15 \%$ of patients and orchi- 
tis in as many as $50 \%$ of post-pubertal males in other studies [12].

In conclusion, Bosnia and Herzegovina is currently facing a large outbreak of mumps with an incidence of 225.8 in the Federation of Bosnia and Herzegovna, in the first half of 2011 . The outbreak is probably related to failures to vaccinate during the war and post-war period between 1992 and 1998. Monitoring of the immunisation status and vaccine effectiveness, high vaccination coverage rates with two doses, and catchup campaigns are necessary to avoid measles, mumps or rubella outbreaks in the future.

\section{References}

1. Karakaš S, Tandir S. Epidemiologija [Epidemilogy]. Univerzitet u Zenici, Zdravstveni fakultet. Print-GS. Travnik 2009; 231-234. Bosnian.

2. Watson IC, Hadler SC, Dykewicz CA, Reef S, Phillips L.

Measles, mumps, and rubella--vaccine use and strategies for elimination of measles, rubella, and congenital rubella syndrome and control of mumps: recommendations of the Advisory Committee on Immunization Practices (ACIP). MMWR Recomm Rep. 1998;47(RR-8):1-57.

3. Gaon J, Terzin AL. Some viral and rickettsial infections in Bosnia and Herzegovina; a sero-epidemiological study. Bull World Health Organ. 1956;15(1-2):299-316.

4. Institute of Public Health, Federation of Bosnia and Herzegovina, Sarajevo, Bosnia and Herzegovina. Epidemiological bulletins of the Institute of Public Health, volumes 16-28, 1997-2009.

5. Stein-Zamir C, Shoob H, Abramson N, Tallen-Gozani E, Sokolov I, Zentner G. Mumps outbreak in Jerusalem affecting mainly male adolescents. Euro Surveill. 2009; 14(50):pii=19440. .Available from: http://www.eurosurveillance.org/ViewArticle. aspx?Articleld $=19440$

6. Centers for Disease Control and Prevention (CDC). Mumps epidemic - United Kingdom, 2004-2005. MMWR Morb Mortal Wkly Rep. 2006;55(7):173-5.

7. Dayan GH, Quinlisk MP, Parker AA, Barskey AE, Harris ML Schwartz JM, et al. Recent resurgence of mumps in the United States. N Engl J Med. 2008;358(15):1580-9.

8. Barskey AE, Glasser JW, LeBaron CW. Mumps resurgences in the United States: A historical perspective on unexpected elements. Vaccine. 2009;27(44):6186-95.

9. Trninic S, Bajraktarevic A. Adverse reactions in estimation of MMR vaccination validation in Bosnian population. Med Arh. 2009;63(4):228-30.

10. Hukic M, Hübschen IM, Seremet M, Salimovic-Besic I, Mulaomerovic M, Mehinovic N, et al. An outbreak of rubella in the Federation of Bosnia and Herzegovina between December 2009 and May 2010 indicates failure to vaccinate during wartime (1992-1995). Epidemiol Infect. 2011:1-7.

11. Kremer JR, Brown KE, Jin L, Santibanez S, Shulga SV, Aboudy Y, et al. High genetic diversity of measles virus, World Health Organization European Region, 2005-2006. Emerg Infect Dis. 2008;14(1):107-14.

12. Walker J, Huc S, Sinka K, Tissington A, Oates K. Ongoing outbreak of mumps infection in Oban, Scotland, November 2010 to January 2011 Euro Surveill. 2011;16(8):pii=19803. Available from: http://www.eurosurveillance.org/ViewArticle. aspx?Articleld $=19803$

13. Karagiannis I, Lier A, Binnendijk R, Ruijs H, Fanoy E, ConynVan Spaendonck MA, et al.. Mumps in a community with low vaccination coverage in the Netherlands Euro Surveill. 2008;13(24):pii=18901. Available from: http://www. eurosurveillance.org/ViewArticle.aspx?Articleld=18901

14. Atkinson W, Wolfe S, Hamborsky J, Mclntyre L, editors. Epidemiology and Prevention of Vaccine-Preventable Diseases. 11th ed. Centers for Disease Control and Prevention (CDC). Chapter 13: Mumps. Washington, D.C.: Public Health Foundation; 2011. p.205-215. Available from:http://www.cdc. gov/vaccines/pubs/pinkbook/default.htm 